\title{
INFLUENCE OF ENERGY BAND DISTORTION ON THE HALL EMF IN BIPOLAR SEMICONDUCTORS
}

\author{
A. Konin \\ Semiconductor Physics Institute, A. Goštauto 11, LT-01108 Vilnius, Lithuania \\ E-mail: konin@pfi.lt
}

Received 24 March 2006

\begin{abstract}
A theory of the Hall electromotive force (emf) in bipolar semiconductors accounting for the boundary conditions in a real metal-semiconductor junction and distortion of energy bands near semiconductor surface is presented. It is shown that the Hall emf essentially depends on the surface potential under certain sample surface and bulk parameters.
\end{abstract}

Keywords: the Hall electromotive force (emf), equilibrium built-in electric field, diffusion-recombination (DR) mode, screening (S) mode

PACS: 72.15.Jf, 73.20.At

\section{Introduction}

It is known that the Hall emf arises in semiconductor owing to the action of the Lorenz force [1]. Under this force, the flux of electron-hole pairs (EHP) occurs in a bipolar semiconductor sample from one surface to the opposite one. The result is the carrier density redistribution [2], which influences the Hall emf value. The Hall emf is measured across the metallic contacts, which also have influence on emf formation: the non-equilibrium electrons can cross the metalsemiconductor junction (MSJ). The above-mentioned causes have influence on the Hall emf value. This influence may be taken into account in the framework of quasi-neutrality approximation (by analogy with the thermo-emf [3]). Besides that, the distortion of energy bands [4] creates the equilibrium built-in electric field. This field separates the non-equilibrium carriers and acts upon the non-equilibrium space charge region (screening mode [5]) formation. The exact solution of the continuity equations and the Poisson equation together with the boundary conditions [6] shows that the Dember emf essentially depends on the surface potential [7]. One may expect such behaviour of the Hall emf in samples with thickness less than the diffusion length.

This article is aimed at the development of the Hall emf theory in bipolar semiconductors.

\section{Theory}

Let us consider a bipolar semiconductor plate $(-a \leq$ $x \leq a$ ). We assume that the plate thickness essentially exceeds the Debye screening length [4]. The external electric field $E$ is applied along the $y$ axis and the external weak magnetic field $B$ is applied along the $z$ axis.

In linear approximation the non-equilibrium densities of electrons $\delta n$, holes $\delta p$, and non-equilibrium electric potential $\delta \varphi$ are obtained from the continuity equations $[7,8]$ and the Poisson equation

$$
\begin{gathered}
\frac{1}{e} \frac{\partial j_{n}}{\partial x}-\frac{\delta n}{\tau_{n}}-\frac{\delta p}{\tau_{p}}=0, \\
\frac{1}{e} \frac{\partial j_{p}}{\partial x}+\frac{\delta n}{\tau_{n}}+\frac{\delta p}{\tau_{p}}=0, \\
\frac{\mathrm{d}^{2} \delta \varphi}{\mathrm{d} x^{2}}=\frac{e}{\varepsilon \varepsilon_{0}}(\delta n-\delta p),
\end{gathered}
$$

where $-e$ is the electron charge, $\tau_{n}\left(\tau_{p}\right)$ is the time characterizing the electron (hole) bulk recombination rate [4], $\varepsilon$ is the semiconductor electrical permittivity, and $\varepsilon_{0}$ is the vacuum permittivity.

The equations for currents in linear approximation by small parameters $|\delta n| / n_{0} \ll 1,|\delta p| / p_{0} \ll 1$, and $|\delta \varphi| \ll k T / e$ take the form $[1,7]$

$$
j_{n}=-e \mu_{n} n_{\mathrm{eq}}\left[\frac{\mathrm{d}}{\mathrm{d} x}\left(\delta \varphi-\frac{k T}{e} \frac{\delta n}{n_{\mathrm{eq}}}\right)+\gamma \mu_{n} E B\right],
$$




$$
j_{p}=-e \mu_{p} p_{\text {eq }}\left[\frac{\mathrm{d}}{\mathrm{d} x}\left(\delta \varphi+\frac{k T}{e} \frac{\delta p}{p_{\text {eq }}}\right)-\gamma \mu_{p} E B\right],
$$

where $\mu_{n}\left(\mu_{p}\right)$ is the electron (hole) mobility, $k$ is the Boltzmann constant, $T$ is the temperature of the semiconductor, $n_{0}\left(p_{0}\right)$ is the equilibrium density of electrons (holes) in the bulk of the sample, $n_{\mathrm{eq}}(x)$ and $p_{\text {eq }}(x)$ are the equilibrium densities of electrons and holes, $\varphi_{\text {eq }}(x)$ is the equilibrium electric potential, and $\gamma$ is the Hall factor.

The equilibrium densities and potential for special cases are obtained in [4].

The boundary conditions (BCs) on a real MSJ are obtained in [6]:

$$
\begin{aligned}
\left.\frac{1}{e} j_{p}\right|_{x= \pm a} & = \pm\left.\nu \delta p\right|_{x= \pm a}, \\
\left.\delta n\right|_{x= \pm a} & =0 \\
\left.\delta \varphi_{\mathrm{M}}\right|_{x= \pm a} & =\left.\delta \varphi\right|_{x= \pm a},
\end{aligned}
$$

where $\nu$ is the surface recombination rate (SRR) and $\delta \varphi_{\mathrm{M}}$ is the variation of electric potential of metallic contact. For simplicity we assume that SRR values at surfaces $x= \pm a$ coincide. Note that in our considered case $\nu$ is the real SRR unlike the SRR values used in quasi-neutrality models [2].

Taking into consideration that the diffusion length significantly exceeds the Debye length we obtain the solution of Eqs. (1), (2), and (6) as a sum of two modes [3]: diffusion-recombination (DR) mode and screening (S) mode. These modes are denoted by subscripts $\mathrm{R}$ and $\mathrm{S}$ accordingly:

$$
\begin{aligned}
& \delta n=\delta n_{\mathrm{R}}+\delta n_{\mathrm{S}}, \quad \delta p=\delta p_{\mathrm{R}}+\delta p_{\mathrm{S}}, \\
& \delta \varphi=\delta \varphi_{\mathrm{R}}+\delta \varphi_{\mathrm{S}} .
\end{aligned}
$$

DR mode is obtained from the solution of Eqs. (1), (2), (6), (7), and condition of quasi-neutrality $\mid \delta n_{\mathrm{R}}-$ $\delta p_{\mathrm{R}} \mid \ll \delta n_{\mathrm{R}}$. Moreover, the equilibrium densities $n_{\text {eq }}$, $p_{\text {eq }}$, and potential $\varphi_{\text {eq }}$ depend on coordinate $x$ only in a thin layer of a thickness approximately equal to the Debye length. Therefore the equalities $n_{\mathrm{eq}}=n_{0}$, $p_{\mathrm{eq}}=p_{0}$, and $n \varphi_{\mathrm{eq}}=0$ are valid for DR mode. So we derive

$$
\begin{aligned}
& \delta n_{\mathrm{R}}=A \sinh \frac{x}{\lambda}, \quad \delta p_{\mathrm{R}}=A(1-\eta) \sinh \frac{x}{\lambda}, \\
& \delta \varphi_{\mathrm{R}}=A \frac{k T}{e} \frac{\mu_{n}-\mu_{p}}{n_{0} \mu_{n}+p_{0} \mu_{p}} \sinh \frac{x}{\lambda}+\Delta \varphi_{\mathrm{H} 0} \frac{x}{2 a},
\end{aligned}
$$

where $\lambda=\sqrt{D \tau}$ is the diffusion length, $D=$ $(k T / e)\left[\left(n_{0}+p_{0}\right) \mu_{n} \mu_{p}\right] /\left(n_{0} \mu_{n}+p_{0} \mu_{p}\right)$ is the bipo- lar diffusion coefficient, $\tau=\tau_{n} \tau_{p} /\left(\tau_{n}+\tau_{p}\right)$ is the lifetime of EHP in the bulk of the sample, $\eta=$ $\left(\mu_{n}-\mu_{p}\right) /\left(n_{0} \mu_{n}+p_{0} \mu_{p}\right) \cdot \varepsilon \varepsilon_{0} k T /\left(\lambda^{2} e^{2}\right), \Delta \varphi_{\mathrm{H} 0}=$ $2 \alpha \gamma E B\left(\mu_{p}^{2} p_{0}-\mu_{n}^{2} n_{0}\right) /\left(n_{0} \mu_{n}+p_{0} \mu_{p}\right)$ is the classical value of the Hall emf, and $A$ is the factor determined by the BCs.

The continuity equations for $\mathrm{S}$ mode take the form

$$
\frac{\mathrm{d} j_{n \mathrm{~S}}}{\mathrm{~d} x}=0, \quad \frac{\mathrm{d} j_{p \mathrm{~S}}}{\mathrm{~d} x}=0 .
$$

Solving Eqs. (4) and (11) we obtain

$$
\delta n_{\mathrm{S}}=\frac{e n_{\mathrm{eq}}}{k T} \delta \varphi_{\mathrm{S}}, \quad \delta p_{\mathrm{S}}=-\frac{e p_{\mathrm{eq}}}{k T} \delta \varphi_{\mathrm{S}} .
$$

Substituting Eq. (12) into Eq. (3) one gets for S mode

$$
\frac{\mathrm{d}^{2} \delta \varphi_{\mathrm{S}}}{\mathrm{d} x^{2}}=\frac{e^{2}}{\varepsilon \varepsilon_{0} k T}\left(n_{\mathrm{eq}}+p_{\mathrm{eq}}\right) \delta \varphi_{\mathrm{S}} .
$$

With the use of Eqs. (5), (6), (9), (12), and relations [4]

$$
\begin{aligned}
& n_{\mathrm{eq}}( \pm a)=n_{0} \exp \left(\frac{e \varphi^{S}}{k T}\right), \\
& p_{\mathrm{eq}}( \pm a)=p_{0} \exp \left(-\frac{e \varphi^{S}}{k T}\right)
\end{aligned}
$$

we derive

$$
A=\frac{Q E B}{\cosh (a / \lambda)}
$$

where

$$
\begin{aligned}
Q & =\gamma \frac{e \lambda}{k T} \frac{n_{0} p_{0}\left(\mu_{n}+\mu_{p}\right)}{\left(n_{0}+p_{0}\right) F_{\nu}}, \\
F_{\nu} & =1+\frac{\nu \tau}{\lambda} \tanh \left(\frac{a}{\lambda}\right)\left[1+\frac{p_{0}}{n_{0}} \exp \left(-2 Y_{S}\right)\right], \\
Y_{S} & =\frac{e \varphi^{S}}{k T}
\end{aligned}
$$

and $\varphi^{S}$ is the surface potential (SP).

Let us calculate the Hall emf in a common case (without solution of Eq. (13)). It follows from Eqs. (7), (8) that the Hall emf $\varphi_{\mathrm{H}}$ is equal to

$$
\begin{aligned}
\Delta \varphi_{\mathrm{H}} & =\delta \varphi_{\mathrm{M}}(a)-\delta \varphi_{\mathrm{M}}(-a) \\
& =\delta \varphi_{\mathrm{R}}(a)+\delta \varphi_{\mathrm{S}}(a)-\delta \varphi_{\mathrm{R}}(-a)-\delta \varphi_{\mathrm{S}}(-a) .
\end{aligned}
$$

From Eqs. (6), (9), (12), and (14) we derive

$$
\begin{aligned}
\delta \varphi_{\mathrm{S}}(a) & =\frac{k T}{e n_{\mathrm{eq}}(a)} \delta n_{\mathrm{S}}(a)=-\frac{k T}{e n_{\mathrm{eq}}(a)} \delta n_{\mathrm{R}}(a) \\
& =-Q E B \frac{k T}{e n_{\mathrm{eq}}(a)} \tanh \left(\frac{a}{\lambda}\right) .
\end{aligned}
$$


Finally we obtain from Eqs. (10), (15), and (16):

$$
\begin{aligned}
\Delta \varphi_{\mathrm{H}}= & \Delta \varphi_{\mathrm{H} 0}+2 Q E B \frac{k T}{e n_{0}}\left[\frac{n_{0}\left(\mu_{n}-\mu_{p}\right)}{n_{0} \mu_{n}+p_{0} \mu_{p}}\right. \\
& \left.-\exp \left(-Y_{S}\right)\right] \tanh \left(\frac{a}{\lambda}\right) .
\end{aligned}
$$

In conclusion we present the solutions of Eqs. (5), (6), (12), and (13) for S mode at small SP:

$$
\begin{aligned}
\delta n_{\mathrm{S}}= & -Q E B \tanh \left(\frac{a}{\lambda}\right)\left[1-\beta+\beta \frac{\cosh \left(x / r_{\mathrm{D}}\right)}{\cosh \left(a / r_{\mathrm{D}}\right)}\right] \\
& \times \frac{\sinh \left(x / r_{\mathrm{D}}\right)}{\cosh \left(a / r_{\mathrm{D}}\right)} \\
\delta p_{\mathrm{S}}= & Q E B \frac{p_{0}}{n_{0}} \tanh \left(\frac{a}{\lambda}\right)\left[1-\beta+\left(\beta-2 Y_{S}\right)\right. \\
& \left.\times \frac{\cosh \left(x / r_{\mathrm{D}}\right)}{\cosh \left(a / r_{\mathrm{D}}\right)}\right] \frac{\sinh \left(x / r_{\mathrm{D}}\right)}{\cosh \left(a / r_{\mathrm{D}}\right)} \\
\delta \varphi_{\mathrm{S}}= & -Q E B \frac{k T}{e n_{0}} \tanh \left(\frac{a}{\lambda}\right)\left[1-\beta+\left(\beta-Y_{S}\right)\right. \\
& \left.\times \frac{\cosh \left(x / r_{\mathrm{D}}\right)}{\cosh \left(a / r_{\mathrm{D}}\right)}\right] \frac{\sinh \left(x / r_{\mathrm{D}}\right)}{\cosh \left(a / r_{\mathrm{D}}\right)},
\end{aligned}
$$

where

$$
r_{\mathrm{D}}=\sqrt{\frac{\varepsilon \varepsilon_{0} k T}{e^{2}\left(n_{0}+p_{0}\right)}}
$$

is the Debye length and

$$
\beta=\frac{4 n_{0}+2 p_{0}}{3\left(n_{0}+p_{0}\right)} Y_{S} .
$$

\section{Discussion of results}

It follows from Eqs. (10) and (19) that the nonequilibrium potential is equal to its classical value in two cases: the sample is massive ( $a \gg \lambda$ ) or the SRR is large enough $(\nu \gg \lambda / \tau)$. Therefore let us consider thin intrinsic semiconductor sample $(a \ll \lambda)$ with small values of SRR $(\nu \ll \lambda / \tau)$. In this case we derive from Eqs. (10) and (19)

$$
\begin{aligned}
\delta \varphi= & -\frac{\gamma E B}{2}\left[\left(\mu_{n}-\mu_{p}\right) x\right. \\
& \left.+\left(\mu_{n}+\mu_{p}\right) a \frac{\sinh \left(x / r_{\mathrm{D}}\right)}{\cosh \left(a / r_{\mathrm{D}}\right)}\right] .
\end{aligned}
$$

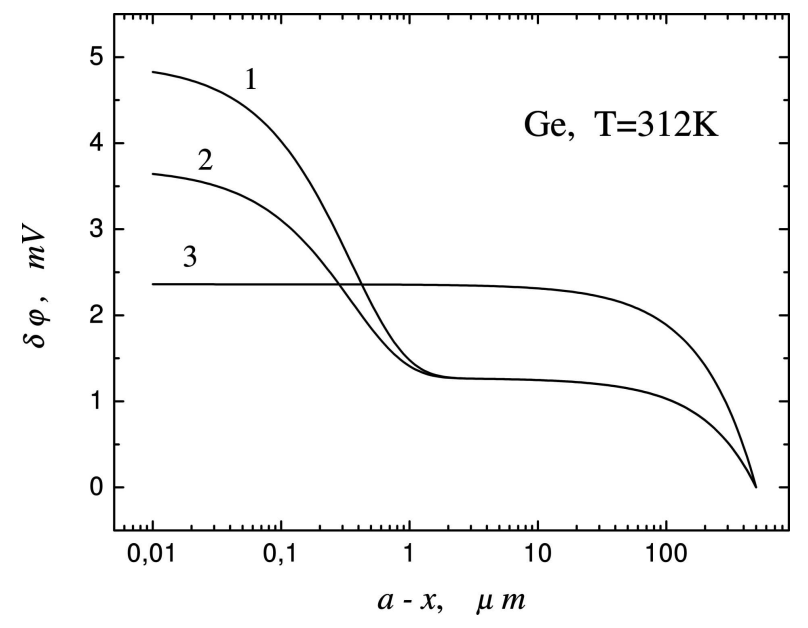

Fig. 1. The Hall potential $\delta \varphi$ distribution in Ge for some SP values: 1 for $\varphi^{S}=-5.4 \mathrm{mV}, 2$ for $\varphi^{S}=5.4 \mathrm{mV}$. Line 3 gives the classical distribution.

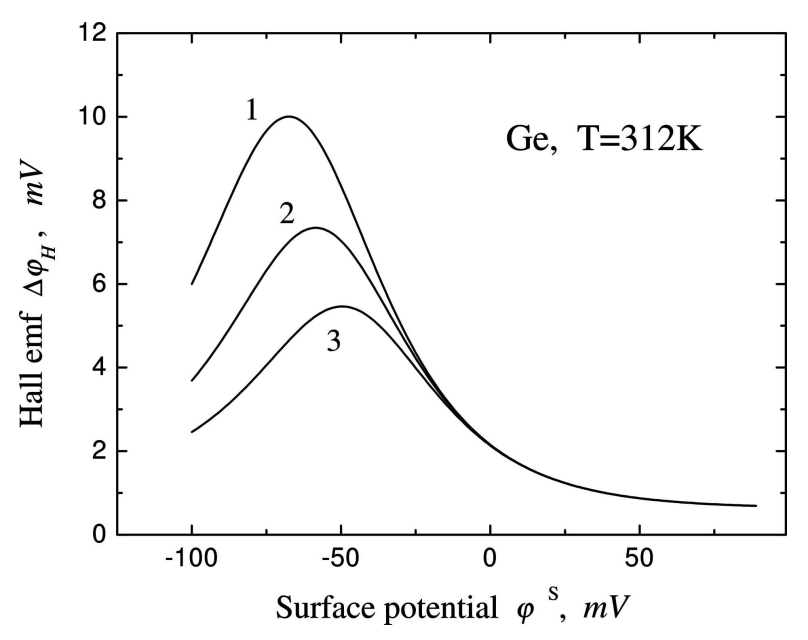

Fig. 2. The Hall emf dependence on SP $\varphi^{S}$ for some SRR values: 1 for $\nu=10 \mathrm{~cm} / \mathrm{s}, 2$ for $\nu=20 \mathrm{~cm} / \mathrm{s}, 3$ for $\nu=40 \mathrm{~cm} / \mathrm{s}$.

As it follows from Eq. (20) $|\delta \varphi|$ is two times less than classical potential distribution [1] in the bulk of the sample and is more than $0.5 \varphi_{\mathrm{H} 0}$ at the surfaces $x= \pm a$.

The distribution of non-equilibrium electric potential in pure $\mathrm{Ge}(T=312 \mathrm{~K}, \lambda=0.1 \mathrm{~cm}, a=0.05 \mathrm{~cm}$, $\mu_{n}=3800 \mathrm{~cm}^{2} /(\mathrm{V} \cdot \mathrm{s}), \mu_{p}=1800 \mathrm{~cm}^{2} /(\mathrm{V} \cdot \mathrm{s}), r_{\mathrm{D}}=$ $3.5 \cdot 10^{-5} \mathrm{~cm}, E=-10 \mathrm{~V} / \mathrm{cm}, B=2 \cdot 10^{-2} \mathrm{~T}$ ) for SRR $\nu=40 \mathrm{~cm} / \mathrm{s}$ is shown in Fig. 1. Curve 3 represents the classical potential distribution, that is $\varphi_{\mathrm{H} 0} x /(2 a)$. It is seen that $\delta \varphi$ value in the region $499<x \leq 500 \mu \mathrm{m}$ is determined by both DR and $\mathrm{S}$ modes and in the region $0<x \leq 499 \mu$ m by DR mode only.

The Hall emf dependence on the SP in pure Ge $(E=$ $-2.5 \mathrm{~V} / \mathrm{cm}$ and the other parameters are the same as in 
Fig. 1) for some SRR values is shown in Fig. 2. As it is seen the Hall emf has a maximum $\Delta \varphi_{\mathrm{D} \text {. MAX }}$ at

$$
\varphi^{S} \approx \frac{k T}{2 e} \ln \left[\frac{\nu \tau p_{0}}{\lambda n_{0}} \tanh \left(\frac{a}{\lambda}\right)\right] .
$$

The value of $\Delta \varphi_{\text {D. MAX }}$ essentially exceeds the classical Hall emf $\left(\Delta \varphi_{\mathrm{H} 0}=1.18 \mathrm{mV}\right)$ and strongly depends on SRR.

These features peculiar to the Hall emf in bipolar semiconductors are conditioned by two reasons: $(i)$ the non-equilibrium electrons can cross the MSJ, (ii) the built-in electric field $E_{\text {eq }}=-\mathrm{d} \varphi_{\text {eq }} / \mathrm{d} x$ changes the $\mathrm{S}$ mode carrier density and so changes the Hall emf.

\section{Conclusions}

The theory of the Hall emf accounting for the distortion of energy bands near semiconductor surfaces has been developed. It is shown that the Hall emf essentially depends on the surface potential for small enough surface recombination rates in samples with thickness less than the diffusion length.

\section{References}

[1] P.S. Kireev, Fizika Poluprovodnikov (Vysshaya Shkola, Moscow, 1975) [Semiconductors Physics, in Russian].

[2] G.E. Pikus, J. Techn. Phys. 26, 22 (1956).

[3] Yu.G. Gurevich, G.N. Logvinov, I.N. Volovichev, G. Espejo, O.Yu. Titov, and A. Meriuts, Phys. Status Solidi B 231, 278 (2002) .

[4] V.L. Bonch-Bruevich and S.G. Kalashnikov, Fizika Poluprovodnikov (Nauka, Moscow, 1977) [Physics of Semiconductors, in Russian].

[5] M. Krčmar and W.M. Saslow, Phys. Rev. B 65, 2333131 (2002).

[6] A. Konin, Lithuanian J. Phys. 46, 233 (2006).

[7] A. Konin, Lithuanian J. Phys. 45, 373 (2005).

[8] I.N. Volovichev and Yu.G. Gurevich, Semiconductors 35, 306 (2001).

\title{
ENERGIJOS JUOSTŲ IŠKRAIPYMO ITTAKA HOLO ELEKTROVARAI BIPOLINIUOSE PUSLAIDININKIUOSE
}

\author{
A. Konin \\ Puslaidininkiu fizikos institutas, Vilnius, Lietuva
}

\section{Santrauka}

Pateikiama Holo elektrovaros (EV) teorija, kurioje atsižvelgta i nepusiausvirojo krūvininkų tankio ir elektrinio potencialo kraštines sąlygas realioje metalo ir puslaidininkio sandūroje ir energi- jos juostų kreivumą puslaidininkio paviršiuje. Irodyta, kad plonesniuose už difuzijos ilgi bandiniuose, jei paviršinès rekombinacijos sparta nedidele, Holo EV priklauso nuo paviršiaus elektrinio potencialo. 